\title{
La etiología como forma de composición de la Peste de Atenas en Tucídides y en Lucrecio
}

\author{
Antonio Ruiz Castellanos \\ Universidad de Cádiz \\ antonio.ruizcastellanos@uca.es
}

Recibido: 22 de diciembre de 2011

Aceptado: 4 de junio de 2012

\section{RESUMEN}

Pretendo hacer ver la influencia del episodio de la Peste de Atenas de la Guerra del Peloponeso de Tucídides sobre el epílogo del libro VI del De rerum natura de Lucrecio en su forma de composición. El episodio lucreciano de la Peste (vv. 6.1138-1286) no constituye un fragmento autónomo, sino que está en función de exornatio del argumento etiológico que le precede, que se desarrolla en los vv. 6.10901137; este argumento, como tipo de texto o modus tractandi, consiste en una etiología triple: unde ortum

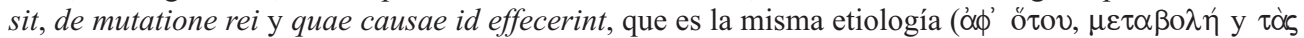
$\alpha i \tau i ́ \alpha$ ) que Tucídides formula en la Guerra del Peloponeso (2.48.3), al comienzo de su descripción de la Peste de Atenas. Todavía más, ambos autores desarrollan el episodio de la Peste siguiendo como guión precisamente esa triple etiología; y en el caso de Lucrecio, reiterando la triple etiología tanto en el fragmento (6.1090-1137) relativo a la enfermedad y a los contagios, como en la propia descripción de la Peste (6.1138.1286).

Palabras clave: Peste de Atenas en Tucídides y Lucrecio. Etiología como tipo de texto o modus tractandi. Ruiz Castellanos, A., «La etiología como forma de composición de la Peste de Atenas en Tucídides y en Lucrecio», Cuad. Fil. Clás. Estud. Lat. 32.1 (2012) 7-34.

\section{The Plague of the Peloponnesian War: The modus tractandi in Thucydides and Lucretius}

\begin{abstract}
I intend to see the influence of the episode of the Plague of the Peloponnesian War of Thucydides on the epilogue of the VI Book of De rerum natura of Lucretius. The Lucretian Pest fragment is not an independent but dependent as an exornatio on the etiology that he develops in vv. 6.1090-1137; this

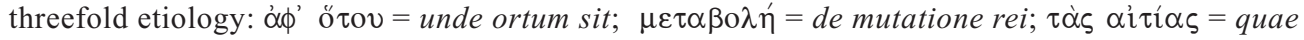
causae id effecerint, is the formula with which Thucydides (2.48.3) begins his account of the Plague. Even more, both authors also developed the Plague following the same etiology.
\end{abstract}

Keywords: Plague of Athens in Thucydides and Lucretius. Threefold etiology as modus tractandi.

Ruiz Castellanos, A., «The Plague of the Peloponnesian War: The modus tractandi in Thucydides and Lucretius», Cuad. Fil. Clás. Estud. Lat. 32.1 (2012) 7-34.

Sumario 0. Introducción. Nuestro objetivo. 1. La etiología como tipo de texto en el De rerum natura de Lucrecio. 1.1. Epílogo argumentativo del libro VI. 1.2. Función argumentativa de las exornationes. 2. Los textos. 2.1. La etiología de la enfermedad y del contagio en Lucrecio. 2.1.1. Quae causa id effecerit. 
2.1.2. Unde ortum sit: Demostración y confirmación. 2.1.3. De mutatione rei. 2.2. La Peste de Atenas en Lucrecio y en Tucídides: 2.2.1. Origen: Unde ortum sit. 2.2.2. De mutatione rerum $=\mu \varepsilon \tau \alpha \beta о \lambda \eta$. 2.2.3. Quae causa id effecerit $=\alpha i \tau i ́ \alpha$. Vis morbida $=\delta \dot{v} \nu \alpha \mu \iota$. 3. Referencias bibliográficas.

\section{INTRODUCCIÓN. NUESTRO OBJETIVO}

La peste ha sido en todas las épocas un azote de la Humanidad, desde las Plagas de Egipto (Éxodo 11.5) hasta la plaga contemporánea del VIH/sida, cuyos efectos nosológicos, poblacionales, sociológicos y psicológicos estamos sufriendo en pleno siglo veintiuno. Es también un tema literario clásico a la vez que contemporáneo (Albert Camus o Alejo Carpentier han escrito sobre la peste), pero ya en la primera obra clásica, la Iliada, se desarrolla el sitio de Ilión en medio de una peste enviada por Apolo en castigo por un delito religioso que había que purificar a base de rituales ${ }^{1}$.

La obra que primero ha descrito literariamente la peste detallando los síntomas, la más conocida e influyente entre griegos y romanos, ha sido el relato de Tucídides sobre la peste que asoló Atenas el año 430 a.C. (y que el propio autor padeció) en su obra La guerra del Peloponeso (2.47-54). Por un lado recoge las influencias técnicas del Corpus Hippocraticum ${ }^{2}$, como lo demuestra el vocabulario que comparte con él (Page 1953, pp.97-119; Lichtenthaeler 1965, passim); y por otro, ha convertido su descripción de la peste de Atenas en el informe modelo para las restantes plagas históricas ${ }^{3}$, hasta llegar a la peste de la época de Justiniano (541 p.C.), que describe Procopio ${ }^{4}$. En la Literatura Latina está también presente la peste como contagio colectivo. Nosotros vamos a observar el tratamiento que de ella hace Lucrecio (6.1093-1286), pero no es el único escritor latino que se ha ocupado del fenómeno 5 .

\footnotetext{
${ }^{1}$ Hom.Il.1.42-53. También Sófocles, en el Oedippus Tyrannus, describe la peste que asola Tebas, que Tiresias descubre que es debida al comportamiento del rey.

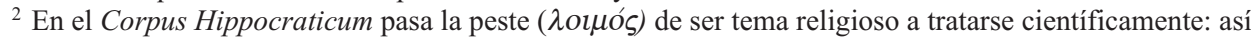
en Prognostica y en De epidemiis I \& III (obras que se admite son auténticas y de finales del s. V; así Proctor [1980, p.129]); por lo que nada tiene que extrañar que estén en la base del tratamiento de Tucídides. En De aere la infección colectiva se hace recaer sobre el medio ambiente que respiran todos los habitantes de un sitio $(\pi \nu \varepsilon v \hat{\nu} \alpha$ y $\mu$ í $\alpha \sigma \mu \alpha)$. El tratado pseudoaristotélico, Problemata 7.887a 22-24 (s. III a.C.) se cuestiona ya la peste como contagio de la siguiente forma: «ipor qué unas enfermedades ( $\phi \theta i \sigma l \varsigma, o b \theta \alpha \lambda \mu i \alpha$ y $\psi \omega \omega \rho \alpha$ ) se transmiten, mientras que otras no?».

${ }^{3}$ Galeno describe una peste que él pasó y de la que sobrevivió (la peste Antonina del año 165); distingue

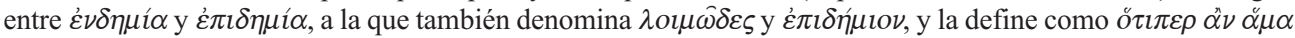

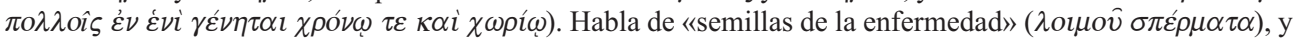
de la predisposición de los cuerpos al contacto. No podemos esperar de la medicina antigua un concepto de 'contagio' o infección colectiva (infectio, contagium) microbiológica, tal como ha sido caracterizada a partir de Robert Koch (1843-1910). Ningún médico antiguo habría podido observar sin microscopio las 'semillas', animalcula o efflunia portadoras del contagio.

${ }^{4} \mathrm{La}$ influencia de la Peste de Tucídides en los escritores de historia es caricaturizada por Lvcian.AleX.Hist.conscr.15. Hace ver cómo es objeto de imitación por Crepereius Calpurnianus (Vossius lo cita entre los historiadores griegos [ed. Westermann, p.422]), quien calca párrafos enteros de Tucídides.

${ }^{5}$ Virgilio la ha tratado en Georgica. 3.474-566; y Livio en Ab urbe condita 3.6.2-7; 25.26.7-11; Ovidio en Metamorphoses 7.523-613; Manilio en Astronomica 1.880-895; Séneca en Oedipus 110-201; Lucano en Pharsalia 6.80-105; Silio Itálico en Punica 14.580-617. Además de otros muchos autores secundarios.
} 
Pretendemos observar la influencia de Tucídides sobre Lucrecio, que unos críticos cifran en un aspecto y otros en otro, y que nosotros vamos a hacer radicar únicamente en el aspecto compositivo, analizando el modus tractandi que utiliza cada uno de los dos autores en su descripción de la referida peste de Atenas.

No vamos a fijarnos en el trabajo ya hecho por otros comentaristas y editores 6 , que detallan las más mínimas discrepancias (8 ó 9 días en vez de 7 ó 9 en LuCR.6.1197) que se dan entre los dos autores; ni tampoco consideramos el vocabulario procedente de Tucídides, prestado, calcado o interpretado no siempre con exactitud por Lucrecio; lo que lleva a los críticos a postular una fuente intermedia ${ }^{7}$.

No haremos crítica literaria ${ }^{8}$, ni analizaremos las diferencias de estilo que se dan entre ambos autores, uno en prosa y el otro en verso, con una mayor o menor expresividad y énfasis.

No vamos a hacer radicar las diferencias, por muy justificadas que estén, en la diferente actitud psicológica con que se implican los autores en el tema; ni en los calificativos y amplificaciones que diferencian la descripción lucreciana respecto de la de Tucídides: «the marked tendency to regard the plague less in physical terms than in emotional, moral, and psychological ones», según expresión de H. S. Commager Jr. (1957, pp.105-118); ni en la función didáctica y moral, que según Stoddard (1996) caracteriza al De rerum natura. No perseguimos el significado simbólico (pesimismo, optimismo relativo, optimismo), que comporta el hecho de que la peste ocupe el lugar de conclusión del texto del De rerum natura; y más si se la contrapone al Himno a Venus. Surge de nuevo la tesis del Lucrecio y el Antilucrecio subyacentes a la obra (Regenbogen 1961, pp.362-277). O incluso la tesis de J. Bayet (1948, p.64) sobre su incompletitud al echar de menos una descripción de la ataraxia y de la felicidad divina tras el relato de la peste, tal como el autor anunció en el libro V 155 y siguientes. $^{9}$

Es legítimo cuestionarse cómo se compagina este epílogo con el correspondiente prólogo del libro VI: ueridicis igitur purgauit pectora dictis / et finem statuit... timoris (24-25). Parece que los sentimientos patéticos que suscita la peste, el miedo al contagio y su imposible evitación, no se compaginan con la calma del sabio, con la actitud de un epicúreo éticamente moderado en sus deseos y ansiedad. En el libro V a cada logro del progreso técnico le acompañaba una proposición sobre su valor moral y la actitud correspondiente. Por lo mismo, en este momento de desesperación, podría preguntarse: ¿qué se puede hacer?, ¿qué cabe esperar? Pero no se trata de dar consuelo ni sentido a lo que no lo tiene. Estamos ante una situación patética, no ética, para la que no cabe más ratio que la curación médica. No es el 'examen' ni la 'prueba final' (Clay

\footnotetext{
${ }^{6}$ Munro (1864, pp.406-417); Bailey (1947, pp.1723-44); Ernout y Robin (1925, pp.359-60). La valoración y búsqueda de significado de la Peste en Lucrecio es una uexatissima quaestio. (ver la bibliografía final) capaz de desalentar una nueva investigación.

${ }^{7}$ En este sentido, W. Luck (1932) conjetura a Demetrio Lacón, epicúreo del s. II a.C., como fuente intermedia (Contra, recensión de Reizenstein (1933, pp.542-549).

${ }^{8}$ Puede verse en Paratore-Pizzani (1960, pp.521-522).

${ }^{9}$ Lo mismo en Paratore (1945, pp.195 y 318-322), quien echa de menos, además del tema de la ataraxia, el de la isonomía; en. Bignone (1945, pp.318-322); o en Kenney (1977, pp.22-23).
} 
2001, p.158) de sabiduría epicúrea a que se somete al lector-discípulo ${ }^{10}$. De ninguna forma cabe comparar este texto ${ }^{11}$ con el de Diógenes de Enoanda (fr. 2 col. ii 7), en que se compara la falta de sentido ético con la peste por su generalización entre la población y propone $\tau \alpha \dot{\alpha} \tau \hat{\zeta} \sigma \omega \tau \eta \rho i ́ \alpha \varsigma \phi \alpha ́ \alpha \mu \alpha \kappa \alpha$, ya que a la inversa no vale: una peste no se corta a base de moral. El libro y la obra De rerum natura desde luego no tienen un bonito final, acaban sin contemplaciones mal, renuncian al musaeum mel.

No obstante es en el prólogo del libro VI, aparentemente la antítesis del epílogo, donde se ofrece la mejor y más auténtica comprensión del epílogo. En él se habla del ateniense Epicuro (Graius homo), que fue consciente de que el progreso material (artibus ad summum donec uenere cacumen, 5.1457) no es capaz de evitar la crueldad de la naturaleza y del azar ${ }^{12}$ :
... Athenae
et recreauerunt uitam legesque rogarunt,
et primae dederunt solacia dulcia uitae,
cum genuere uirum tali cum corde repertum /(...)/
ueridicis igitur purgauit pectora dictis
et finem statuit cuppedinis atque timoris
exposuitque bonum summum quo tendimus omnes
quid foret, atque uiam monstrauit, tramite paruo
qua possemus ad id recto contendere cursu,
quidue mali foret in rebus mortalibu' passim,
quod fieret naturali uarieque uolaret
seu casu seu ui, quod sic natura parasset. 6.2-31

La resolución del epílogo y de la obra remite a este prólogo en el que Epicuro no sólo expresa los límites y alcance del deseo y del temor, del bien supremo al que tendemos y que nos es accesible a todos, sino que también es consciente de los males que el azar y la naturaleza nos deparan. ${ }^{13}$

Schrijvers (1970, p.324) afirma: «N'est-il pas le but que Lucrèce a voulu atteindre avec ce finale: inciter le lecteur à recommencer la lecture du poème?». De la forma más agudamente antitética pasaríamos de «habitar una ciudad sin murallas ante la muerte», de la cruel naturaleza, a la madre Tierra, «cuya cabeza se ciñe con una corona mural, simbolizando con ello que protege las ciudades con sus fortalezas» $(2.606-607)^{14}$.

\footnotetext{
${ }^{10}$ El principio que se expresó en el libro III sobre la muerte como reguladora ecológica: materies opus est ut crescant postera saecla /.../ sic alid ex alio numquam desistet oriri (3.965-970), por más razonable que sea en general, no le sirve a quien la padece en esas circunstancias. Quizás podía haberse aplicado el Tetrafármaco en lo referente al dolor y a la muerte, pero sólo en aquello que tiene de negativo: los sentidos no llegarán a percibir ni el extremo dolor ni la propia muerte.

${ }^{11}$ Contra Commager (2007, p.190).

12 Diog.LAer. Vitae phil. 10.22, cuenta la reacción de Epicuro ante el dolor.

13 La misma actitud que se expresa en el frag. 339 de Usener: «sobre cualquier otra cosa se pueden tomar medidas ante una necesidad, pero en lo que respecta a la muerte, habitamos todos una ciudad sin murallas»».

${ }^{14}$ Se trata del principio de isonomia (la vida y la creación compensadas con la muerte y la decadencia, y a la inversa), que Lucrecio «ha proprio applicato nel poema... ma profilandola sotto l'aspetto esasperato del contrasto», Paratore-Pizzani (1960, pp.524-525).
} 


\section{LA ETIOLOGÍA COMO TIPO DE TEXTO EN EL DE RERUM NATURA DE LUCRECIO}

Lo que Lucrecio se está planteando al final de su obra (6.1093-1286) es el origen de la enfermedad y de las epidemias, porque así lo exige el género literario de todo el libro VI con el que acaba el De rerum natura. Todo el libro ofrece etiologías capaces de explicar los fenómenos extraños o mirabilia; si no mediante etiologías únicas, sí al menos mediante etiologías múltiples ( $\pi \circ \lambda \lambda \alpha \chi \omega \hat{\omega}$ $\alpha i \tau \imath o \lambda o \gamma \varepsilon \hat{\imath} \nu)$, para hacer ver que los fenómenos más paradójicos tienen alguna explicación racional; todo menos dejar en manos de la religión y el mito la explicación de este tipo de fenómenos, que se convierten en trascendentes desde el momento que están fuera del alcance de los sentidos, por ser subterráneos, celestes o microscópicos.

Otras interpretaciones que se quieran ver en este texto, tal como el pesimismo de nuestro autor y su concepción de la vulnerabilidad de la vida, la insignificancia de la religión cuando llega el momento de la verdad, etc., se pueden plantear como acompañamiento dentro de la partitura, pero no como clave de su explicación. Nosotros vamos a poner el énfasis en el modus tractandi o tipo de texto de este fragmento porque ahí es donde esperamos encontrar la clave.

Lo habitual es achacar a la psicología enfermiza de Lucrecio (su pesimismo, melancolía o incluso psico-patología) el dejar como remate de la obra la descripción de la Peste de Atenas. Victor Hugo ya dijo ${ }^{15}$ : «Ont-ils des Spinoza qui frappent aux murailles, / des Lucrèce niant tout ce qu'on a rêvé, / qui du noir infini feuilletant les registres / ont écrit: Rien, au bas de ses pages sinistres, / et penchés sur l'abîme ont dit: L'oeil est crevé». Para J.B. Logré (1946, p.277); o para L. Perelli (1968, pp.203ss.) este final de la obra no es más que la última pincelada de pesimismo que da el autor. De una forma u otra ven el episodio determinado por el pesimismo, D. F. Bright (1971, pp.607-632), quien ya ve previamente diseñado el fin del libro VI en la historia del progreso del libro V; Minadeo (1965, pp.444-461), que ve en el episodio de la Peste un momento de decadencia en contraposición y contraste con otros momentos creativos; y E.E. Sikes (1936, p.89), que entiende el episodio de la Peste como el triunfo de Marte frente al Himno de Venus. Otros ven en la extensión desmesurada que ocupa la Peste un regodeo morboso de nuestro autor; así C. Salemne (1980, p.80).

El plus que esperamos del final del De rerum natura, como del final de cualquier obra, convierte en simbólico este episodio; sobre todo, por ocuparse de un drama colectivo tan grave, que estuvo a punto de acabar con la misma civilización que se ha elogiado en el prólogo del mismo libro:

Primae frugiparos fetus mortalibus aegris dididerunt quondam praeclaro nomine Athenae et recreauerunt uitam legesque rogarunt et primae dederunt solacia dulcia uitae. 5.1-4

${ }^{15}$ Víctor Hugo, Les Contemplations, XXX, Magnitudo parvi. 1856. 
Aunque también hay quien considera la descripción de la Peste de Atenas una descripción objetiva y que nada tiene de injerencia de los sentimientos del autor. Así P. Ferrarino (1972, p.231) y A. Traglia (1948, p.89); mientras que F. Giancotti (1980, p.197) puede ver en el episodio hasta un relativo optimismo.

Pero lo cierto es que se trata de un episodio que está bien localizado al final del libro VI. Las doxografías recogidas por Aecio en su Epitome a Plutarco y las Eclogae de Estobeo ${ }^{16}$, acaban tratando precisamente el tema de la enfermedad. Está el tema por tanto colocado en su sitio tradicional y así lo habría asumido Lucrecio. La peste es algo horrible, como también son terribles la erupción del Etna (6.639-711), los terremotos (6.535-607) o la fulminación por el rayo (6.219-255), que han sido anteriormente objeto del estudio etiológico del mismo libro sexto del De rerum natura. Sólo el hecho de constituir el último fenómeno mirabile de los múltiples que se examinan en el libro, le da ese carácter simbólico de pesimismo que se quiere ver en él. Si en vez de la peste hubiese sido el terremoto el último fenómeno estudiado, hubiera tenido un aire todavía más catastrófico e incluso apocalíptico el final del libro VI, que es a la vez el final de la obra. Pero lo único que nuestro autor está haciendo en este momento es poner a prueba la capacidad de explicación que tiene el epicureísmo (su ratio), respecto a un fenómeno físico extraordinario, que goza de la mayor complejidad, trascendencia social y dramatismo, como es el de la peste.

\subsection{EPÍLOGO ARGUMENTATIVO DEL LIBRO VI}

Todos los libros del De rerum natura acaban en epílogo: ¿Por qué iba a ser diferente el último libro que es precisamente el final de la obra? Si el Himno a Venus se considera el prólogo fundacional de la obra De rerum natura ${ }^{17}$, el epílogo del libro VI ¿no va a constituir un epílogo auténtico y un remate adecuado de la obra entera?

Pero hay que tener en cuenta que mientras los prólogos lucrecianos son de género epidíctico, los epílogos son en cambio de tipo argumentativo. En los epílogos no cesa la argumentación, siguiendo en ello nuestro autor la preceptiva retórica. El epílogo hace la función de recapitulación ( $\alpha \nu \alpha \kappa \varepsilon \phi \alpha \lambda \alpha \imath \omega \hat{\sigma} \sigma \varsigma, \alpha \nu \alpha ́ \mu \nu \eta \sigma \imath \varsigma)$; tiene por objeto fijar ante el juez totam simul causam para que se grabe en su memoria (Qvint.Inst.6.1.1). Una segunda función que Quintiliano (ibidem) le reconoce al epílogo es la de provocar sentimientos fuertes ( $\pi \alpha \dot{\alpha} \theta \varsigma \varsigma)$ de indignación, $\delta \varepsilon \imath \nu \omega \hat{\sigma} \sigma \varsigma$, o

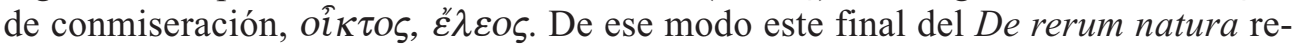
úne las dos cualidades del epílogo: reasume todo el material tratado y lo asume en el mayor grado, con el mayor dramatismo. Cicerón (Inu.1.107), refiriéndose al epílogo, dice:

${ }^{16}$ Diels (1879, pp.442-444). Cf. Sedley (1998, p.158), quien añade las influencias posibles de Teofrasto en Epicuro. Es interesante la correspondencia (p. 158) entre LuCR.6 y AET.3.1-4.8. Cf. Runia (ibidem), «Lucretius and Doxography».

${ }^{17}$ De ahí se toma el título: te sociam studeo scribendis uersibus esse, / quos ego de rerum natura pangere conor vv. 1.24-25 
Id locis communibus efficere oportebit, per quos fortunae uis in omnes et hominum infirmitas ostenditur; qua oratione habita grauiter et sententiose maxime demittitur animus hominum et ad misericordiam comparatur, cum in alieno malo suam infirmitatem considerabit.

Y en Inu.1.100 añade: quoniam tota iterum dici non potest, id elligatur quod erit grauissimum. La peste es de un impacto general gravísimo y angustioso, y a la vez es el fenómeno natural más complejo (micro-biológico por su explicación del contagio y al mismo tiempo ecológico y global); y por todo ello está bien puesta al final.

El libro VI es el último del De rerum natura porque en él se aplican los principios adquiridos en los libros anteriores: el principio de razón suficiente, el de la composición de la materia, el flujo de los átomos, el de la especificidad de los átomos que componen un ser vivo, etc., para resolver problemas aparentemente insolubles, mirabilia. Se sigue en ello la misma forma macro-compositiva que en Geometría, donde se distingue entre demostraciones y problemas ${ }^{18}$, tratándose primero los teoremas y resolviendo después los problemas. En el fenómeno del contagio y de la peste se reasumen los fenómenos microscópicos, los atmosféricos y los geológicos. Estos fenómenos, al estar fuera del alcance de nuestra experiencia, nos producen un sobrecogimiento misterioso, de manera que al dolor y peligro personal y social real de la peste se le añade un sentimiento de impotencia, de sinsentido y de angustia. Los dos aspectos: el racional y el aspecto liberador, pondrán a prueba la capacidad de explicación de la teoría atomista en el epílogo final de la obra.

El aspecto patético, propio de la peste, así como el hecho de ser tan dilatada su descripción en el De rerum natura, no deja ver claramente la función que haya podido dársele en el diseño de la obra. Por otro lado, el hecho de constituir una imitatio (no sólo una alusión) de Tucídides da a entender pretensiones literarias y simbólicas adicionales para el fragmento; por eso se hace radicar en la Peste de Lucrecio un mayor dramatismo, expresividad y contenido psicológico frente al ejemplar que sigue de Tucídides.

\subsection{FUNCIÓN ARGUMENTATIVA DE LAS EXORNATIONES}

El texto de la Peste de Atenas (LuCR.6.1138-1251) se desnaturaliza cuando se lo considera un episodio autónomo con el que se liquida la obra, y no una parte del argumento que le precede y en función del cual opera como ilustración y confirmación. A nuestro modo de ver, la Peste de Atenas no es más que una exornatio, una confirmación de tipo literario dentro del precedente argumento-etiología que trata sobre la enfermedad y las epidemias (LuCR.6.1090-1137). La Peste no es más que una confirmación de la proposición de tipo científico que se enuncia en 6.1090-93:

nunc ratio quae sit morbis aut unde repente mortiferam possit cladem conflare coorta

${ }^{18}$ Procl.In Euc. Prólogo, parte II. Ed. F. Vera (1970, pp.1163-65 y 75-76). 
morbida uis hominum generi pecudumque cateruis expediam.

Los argumentos se componen en el De rerum natura lucreciano (siguiendo a la anónima Rhetorica ad Herennium 3.9.16) en torno a una proposición ${ }^{19}$. Dice esa Retórica:

Non modo totas causas per orationem, sed singulas quoque argumentationes disponemus ... in expositionem, rationem, confirmationem rationis, exornationem, conclusionem.

Distingue, como se ve, dos tipos de dispositio: además de la macro-compositiva o per orationem, i.e., la que se compone de exordio, narración, demostración, refutación y conclusión, otra dispositio micro-compositiva que ordena el discurso a base de parágrafos argumentativos (per argumentationes). Esa dispositio, denominada también 'epiquerema', es la que pone en cabeza aquello que queremos demostrar, explicar o refutar, la propositio o expositio; le hace seguir una o varias rationes para demostrarla, explicar su causa, o fundamentarla; si la ratio precisa a su vez demostración, sigue una (o varias) rationis ratio(nes) o confirmatio(nes) rationis y así sucesiva y recursivamente; finalmente y de forma optativa va una exornatio más una conclusio o complexio en la que se recoge de nuevo y brevemente la proposición y su fundamentación.

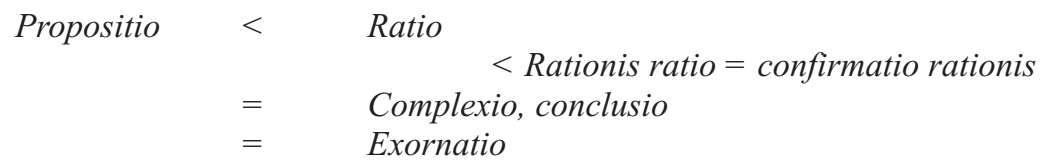

Lo mismo y por extenso se explica en Rhetorica ad Herennium 2.18.27, donde se afirma que ésta es la mejor forma de proceder ornate et absolute tractare. Cicerón (Inu.1.72) la tilda de artificiosa expolitio; Quintiliano también la conoce (Inst.5.10.18). Es una estructura que podríamos llamar 'prototípica', ya que siempre que queremos convencer de algo, aportamos espontáneamente el porqué, i.e., la ratio de nuestra proposición. Longacre (1979, p.124) incluye esta estructura entre los 'binary structure parameters'. De hecho se da esta organización en todos los textos argumentativos, tanto científicos como divulgativos, tanto teóricos como preceptivos de la Literatura Clásica, tanto en el De rerum natura de Lucrecio ${ }^{20}$ como en el Ars Poetica de Horacio, en las Naturales Quaestiones de Séneca o en la Historia Naturalis de Plinio.

Esta forma de composición se da tanto en las demostraciones como en las refutaciones y etiologías.

Estas últimas son consideradas por los analistas del discurso como formas específicas $^{21}$. Se trata de un género en el que se investiga(n) la(s) causa(s) de un fenóme-

\footnotetext{
${ }^{19}$ Marcovic (2008, pp.67\&74) señala que el propio Epicuro coloca al inicio de los argumentos la proposición que se va a demostrar, y la recapitula al final como conclusión, redactando los argumentos en forma de anillo.

${ }^{20}$ Para la estructura de los argumentos lucrecianos, Ruiz Castellanos (1992, pp.69-128).

${ }^{21}$ J.M. Adam (1997) le dedica a la etiología el cap. 5 distinguiéndolas del texto argumentativo, al que le dedica el cap. 4.
} 
no problemático. Las etiologías son características de la Doxografía, un género científico cultivado por Teofrasto (SIMP. fr.7) y Demócrito, y recomendado por Epicuro ${ }^{22}$. Y sostenemos que es la forma compositiva del fragmento lucreciano que analizamos ${ }^{23}$.

El episodio lucreciano de la Peste es por sí solo un fragmento autónomo y menos todavía constituye el epílogo del libro VI como tal. El episodio de la Peste es utilizado por Lucrecio en función de exornatio de la tesis que se defiende en esa etiología que lo precede, confirmando la propositio (6.1090-1093) antes expresada: nunc ratio quae sit morbis... expediam. Las exornationes son confirmaciones de la proposición, aunque con capacidad de ornato como variatio que utiliza ejemplos tomados de distintos campos; son digresiones, que aprovechan motivos míticos, zoológicos, pastoriles e históricos relacionados con el tema (Rhet.Her.3.9.16). En este caso, la Peste es una exornatio que aúna la función de confirmación con la de ornato por alusión, imitatio e incluso aemulatio del mismo episodio en Tucídides; no se priva el autor de su derecho a la variatio (al trasladar un episodio narrativo a la función de confirmación argumental y al pasar una historia en prosa a poema en verso, con la expresividad que le confiere la poesía); y todo ello sin renunciar al uso de la amplificación retórica y expresiva. Quizás no se haya destacado suficientemente este aspecto. No es un episodio aislado, sino la ilustración de una tesis. La Peste de Atenas, dice Salemne (1980, p.80), es «considerata come un esempio di epidemie, rientra nel serrato discorso logico del libro». No es un texto histórico, no es un fragmento de una historia como ocurre en Tucídides, sino una descripción puesta en función de exornatio de un argumento etiológico y por ello forma parte del texto argumentativo que se inicia en 6.1090. G. Müller (1978, p.234) también lo afirma: «The description of the Athenian plague cannot really be separated from the argumentation».

\section{LOS TEXTOS}

\subsection{LA ETIOLOGÍA DE LA ENFERMEDAD Y DEL CONTAGIO EN LUCRECIO}

Fijémonos en el argumento que se desarrolla en el epílogo del libro sexto del $D e$ rerum natura (1190-final). La propositio a demostrar es de tipo etiológico; Lucrecio lo expresa metalingüísticamente: Nunc ratio quae sit... expediam. En forma de cuestión se propone el autor buscar la ratio explicativa o causa del fenómeno de la enfermedad y la peste:

Nunc ratio quae sit morbis aut unde repente mortiferam possit cladem conflare coorta morbida uis hominum generi pecudumque cateruis, expediam, 6.1090-1093.

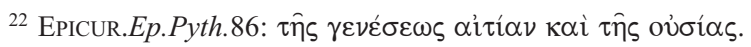

${ }^{23}$ Marcovic (2008. III) estudia la etiología como argumento desde el efecto a la causa y desde la causa al efecto. Más que fijarse en la etiología como modo de la composición, la estudia como argumento tópico. Para la estructura de las etiologías lucrecianas, Ruiz Castellanos (1992, pp.136-159).
} 
Al hablar de etiología nos estamos refiriendo a un argumento con estrategia de búsqueda, que trata de identificar la causa que produce un fenómeno determinado; se trata del procedimiento heurístico por excelencia.

Este tipo de texto es el que va a producir la discrepancia aparente y al mismo tiempo el concierto fundamental compositivo que se da entre la Peste de Tucídides y la de Lucrecio, la una narrativa y la otra cumpliendo la función argumentativa de búsqueda de la causa que produce el fenómeno de la peste. En la Guerra del Peloponeso Tucídides renuncia a explicar la causas de la epidemia, mientras que Lucrecio se empeña en su búsqueda. Tucídides (2.48.3) expresa así su renuncia: «Cada cual, médico o profano, que saque sus conclusiones sobre el origen de este mal

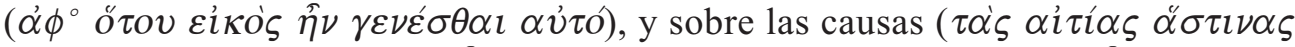

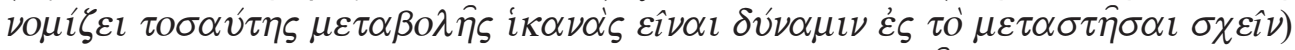
que cree que están operando semejante trastorno $(\mu \varepsilon \tau \alpha \beta o \lambda \bar{\eta} \varsigma) »$. Y sigue: «Yo, por

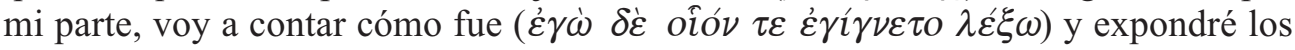
indicios a partir de los cuales uno que los examine, en caso de que de nuevo vuelva a atacar, podría diagnosticarla mejor por contar con una idea previa, al haber estado yo mismo enfermo y haber visto también a muchos otros padecerlo». Lucrecio dirá: «voy a explicar ahora cuál es la causa de la enfermedad y el origen de este brote maligno súbito capaz de esparcir la muerte entre los hombres en masa y entre los animales a manadas». Los dos autores parecen tener objetivos diferentes: Tucídides «para el caso de que de nuevo vuelva a atacar», Lucrecio en cambio para indagar la causa o ratio etiológica.

La etiología es el procedimiento médico por excelencia: conociendo los síntomas se diagnostican o conjeturan las enfermedades o los síntomas que faltan para completar el cuadro clínico. Pero también es el género recomendado y seguido por Epicuro, quien la describe en la Epistula ad Pythoclem 84-86 y 97-99 y en la dirigida $A d$ Herodotum 79; allí distingue los principios que se demuestran (el vacío y los átomos, el infinito, etc.) y los que se explican, casi siempre acudiendo al $\pi \circ \lambda \lambda \alpha \chi \hat{\omega} \varsigma \alpha i \tau \iota o \lambda o \gamma \varepsilon \hat{\imath} \nu$, de la manera que se dice en De rerum natura 6.703-704:

Sunt aliquot quoque res quorum unam dicere causam

Non satis est, uerum pluris, unde una tamen sit.

Tucídides, aun renunciando a dar la etiología de la peste, no deja de ofrecer los raíles en que se ha de mover el argumento de Lucrecio (lo cual delata una influencia radical metodológica de aquel sobre este): «sobre el origen de donde procede este

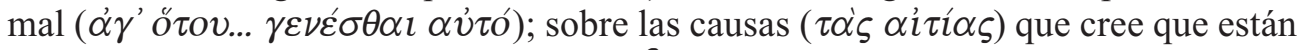
operando, y sobre el trastorno ( $\mu \varepsilon \tau \alpha \beta o \lambda \hat{\eta} \varsigma)$ que produjo» (2.48.3). Lucrecio seguirá de forma explícita los pasos que traza y a los que renuncia aparentemente Tucídides. Tres aspectos causales: el origen, las causas o fuerzas ( $\delta v v \alpha ́ \mu \varepsilon \iota \varsigma$, uires) que trasmiten esa energía, y finalmente la fenomenología o sintomatología del fenómeno de la epidemia ${ }^{24}$.

\footnotetext{
${ }^{24}$ No coincide con la triple etiología que Galeno distingue: la causa contentiua, la causa antecedens y la causa inicial o causa procatarctica, apud Nutton (1983, pp.1-34.). Si se inicia el contagio por una causa
} 
Si atendemos a estos tres aspectos causales: el origen, las causas o fuerzas de la epidemia, y la sintomatología, observamos que las tres causas están ya en el enunciado de la proposición:
Nunc $\mathbf{A})$ ratio quae sit morbis $\mathbf{B})$ aut unde $\mathbf{C}$ ) repente mortiferam possit cladem conflare coorta morbida uis hominum generi pecudumque cateruis, expediam. 6.1090-1093.

E inmediatamente se pasa en el De rerum natura a estudiar una por una las tres causas antedichas: A, B y $\mathbf{C}$.

\subsubsection{QUAE CAUSA ID EFFECERIT}

\section{... primum multarum semina rerum esse supra docui quae sint uitalia nobis, et contra quae sint morbo mortique necessest multa uolare; ea cum casu sunt forte coorta et perturbarunt caelum, fit morbidus aër. 1093-109725}

Sorprende en un epicúreo su recurso a un germen vivo, semina, como causa del contagio. Esa explicación parece más propia de Anaxágoras, al que se le ha criticado (LUCR.1.830-920) que no dé la teoría democrítea y epicúrea del átomo inorgánico. Además parecería que Lucrecio fue el primero y el único en hablar de gérmenes contagiosos, semina morbi, antes de llegar al De contagionibus de G. Fracastoro, aparecido en $1546^{26}$. Y eso ha desencadenado la búsqueda de antecedentes para la teoría lucreciana del contagio: Ernout\&Robin, a.1., dan como antecedente de esta etiología al médico Asclepiades, apoyándose con reservas en Carlo Pascal, Studi critici sul poema di Lucrezio a.l. Bailey (a.1.) habla de Alclepiades de Chios (floruit 95 a.C.) a quien Plutarco asocia con los metodistas y que gozó de un gran predicamento entre los latinos. Otra fuente podía ser Sorano, a quien sigue entre los latinos Caelius Aurelianus (fl. 410 p.C.) ${ }^{27}$. Se aduce también a Varrón (Rust.1.12.2-4), quien habla de animalia quaedam minuta quae non possunt oculi consequi.

Pero esos antecedentes nos parecen más problemáticos que el uso del término semina en nuestro autor. Por semina rerum hay que entender en el De rerum natura los átomos, y no semillas, ni esperma, ni gérmenes, ni animálculos. Lucrecio advierte contra Anaxágoras:

\footnotetext{
externa (procatarctica): calor, frío, etc., que altera el estado del cuerpo, eso dependerá de la predisposición del cuerpo a afectarse por dicha causa (causa antecedens). La causa contentiua, originada por las dos anteriores, lleva a un trastorno corporal, que es la enfermedad.

${ }^{25}$ Señalo en negrita las palabras que cargan con el significado propio de la etiología y subrayo las que hacen de marca sintáctica, así como las expresiones metalingüísticas.

${ }^{26} \mathrm{Si}$ descontamos a IsID. Nat.39: Pestilentia est morbus late uagans et contagio suo quaequae tetigerit polluens. Y en Orig.4.6.8: contagium a contingendo, qui quem tetegerit polluit.

27 Plut.Symp. 8.9.731 B. Cf. CAEL.Aur.,Chronic diseases 4.1.4: p. 817 Drabkin, Chicago 1950
} 
denique iam quaecumque in rebus cernis apertis si fieri non posse putas, quin materiae corpora consimili natura praedita fingas, hac ratione tibi pereunt primordia rerum. 1.915-918.

Con lo cual cierra Lucrecio la posibilidad de buscar causas microscópicas orgánicas para efectos orgánicos, pero utiliza la denominación (y frecuentemente): semina rerum para referirse a los átomos (Roca Melià, 1978): esse ea quae solido atque aeterno corpore constent / semina quae rerum primordiaque esse docemus (1.500-501). Así cuando habla del número limitado de formas de los átomos: primordia rerum / finita uariare figurarum ratione. / quod si non ita sit, rursum iam semina quaedam / esse infinito debebunt corporis auctu. O cuando hace nacer las cualidades sensibles de la combinación de átomos: magni quod refert semina quaeque / cum quibus et quali positura contineantur (2.760-762). No merece la pena citar más lugares ya que la expresión semina rerum es equivalente a primordia, corpora prima, exordia rerum o simplemente átomos o partículas: semina uocis (3.496) semina ignis (4.330); semina simulacris obuia rerum (4.334), etc.

Hay que tomar la palabra semina en el significado de 'corpúsculos', que aun siendo diminutos son capaces de cladem conflare (6.1091) por tener una morbida uis (6.1092). Lucrecio bien puede haber seguido al democríteo Filón, que mantuvo la doctrina de los poros como canales de la enfermedad, tal como lo afirma Plut.Symp. 8.9.731B; 733; 734D. Diels ${ }^{28}$, piensa que Lucrecio sigue un comentario de Demetrio Lacón a los Pronósticos hipocráticos. Robin \& Ernout ad. v.1138, sospechan de «l'existence d'un intermédiaire» entre Tucídides y Lucrecio.

El verdadero mecanismo de la intoxicación es para un epicúreo el de la compatibilidad e incompatibilidad ya explicada en los versos 6.773-776:
et magis magis esse aliis alias animantibus aptas
res ad uitai rationem ostendimus ante,
propter dissimilem naturam dissimilisque
texturas inter sese, primasque figuras.
multa meant inimica per auris, multa per ipsas
insinuant naris infesta atque aspera tactu,
nec sunt multa parum tactu uitanda, neque autem
aspecto fugienda, saporeque tristia quae sint.

La no afinidad entre las diversas sustancias y el cuerpo vivo receptor por la forma de sus poros explica su nocividad. La intoxicación es como la alimentación: ambas se basan en el mismo principio de asimilación o rechazo. Ya se han descrito en versos anteriores ciertas incompatibilidades que resultan perniciosas por la forma de los corpúsculos: de olores e incluso colores y sonidos (la sombra perniciosa de ciertos árboles (783-785); la flor del Helicón que puede ser mortal (786 y sigs.), la mecha mal apagada que provoca la epilepsia (791-793); la mujer que durante el periodo

${ }^{28}$ Diels (1969, p.355). $C f$. Bollack (1978, p.449). 
se duerme al olor del castóreo (794-796); la sombra y el perfume de las plantas que puede ser pernicioso; el león que huye despavorido al canto del gallo; el minero que se agota en la mina (813-15). En el episodio de los Avernos se ha visto cómo los hedores causan la muerte de los pájaros que sobrevuelan el lago:

Principio hoc dico quod dixi saepe quoque ante,

in terra cuiusque modi rerum esse figuras;

multa, cibo quae sunt uitalia, multaque morbos

incutere et mortem quae possint adcelerare. 6.769-772

Y en 6.959-961 se dice: Non omnia.../ corpora... / atque eodem pacto rebus sint omnibus apta. Este mismo modelo explicativo mecanicista se puede encontrar también en Galeno ${ }^{29}$; pero para Lucrecio hasta las descargas eléctricas que se propagan de metal en metal son corpusculares. Se da el contagio como transmisión a través del aire, del agua, de los alimentos y del medio sólido, ya que también los sólidos por ser atómicos son volátiles: multa uolare. El carácter fluido, incluso de los minerales como el imán, y su emanación permanente (6.921-935), está en la base de la explicación de la toxicidad.

\subsubsection{VNDE ORTVM SIT: DEMOSTRACIÓN Y CONFIRMACIÓN}

En este aspecto sigue Lucrecio tanto a Tucídides como el tratado hipocrático Sobre los aires, las aguas y lugares, caps. 1-11. Este tratado confunde medio y causa; dice Vivian Nutton (2000, p.65), citando a Herodiano (Hist.6.6-2) -que cuenta una peste sufrida por el ejército de Alejandro Severo en el 232 p.C.-, que la Medicina en la antigüedad consideraba la peste como una cuestión de inadaptación al clima, no como hoy, que entendemos el contagio como transmisión de gérmenes. Diógenes Laercio, cuando describe en las Vidas de los filósofos la curación producida por Empédocles en Selinus, dice que padecía la ciudad de dysodia, mal olor, poniendo a la misma altura el síntoma y la causa.

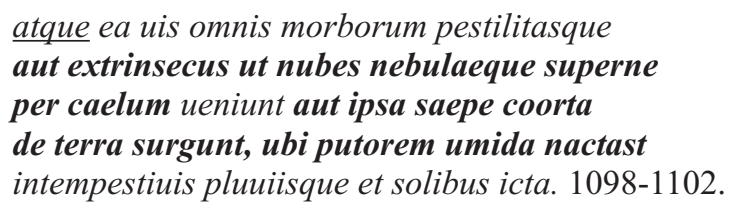

También para Lucrecio el medio facilita e incluso potencia la transmisión de la causa del contagio: la tierra, los charcos, las nubes y nieblas trasladadas por el aire portan la fuerza mórbida y la pestilencia. Esta causa se enlaza con la anterior a través de la cópula atque y mediante el mantenimiento del tópico: ea uis omnis morborum pestilitasque.

\footnotetext{
${ }^{29}$ GaL. On affected parts, Basle, Karge, 1976, VI.5: VIII 421. K
} 


\section{Confirmación de la etiología unde ortum sit} a) nonne uides etiam caeli nouitate et aquarum temptari procul a patria quicumque domoque adueniunt ideo quia longe discrepitant res? b) nam quid Brittannis caelum differre putamus, et quod in Aegypto est, qua mundi claudicat axis, quidue quod in Ponto est differre et Gadibus atque usque ad nigra uirum percocto saecla colore? quae cum quattuor inter se diuersa uidemus quattuor a uentis et caeli partibus esse, tum color et facies hominum distare uidentur largiter et morbi generatim saecla tenere.

c) est elephas morbus qui propter flumina Nili gignitur Aegypto in media neque praeterea usquam. Atthide temptantur gressus oculique in Achaeis

finibus. inde aliis alius locus est inimicus partibus ac membris; uarius concinnat id aër. 6.1103-1119.

El foco de este párrafo confirmativo se dirige a subrayar las diferencias de los distintos lugares bajo distintos cielos y vientos (no parece que haya un mismo orbe celeste para todos) y hacer ver cómo esa diversidad produce diferencias en morbilidad, que es lo que constituía la ratio B. Hay tres pruebas: la primera es la exposición del viajero; la segunda las diferencias entre razas y morbilidad según la región donde se vive; la tercera se compone de tres ejemplos: la enfermedad de la elefantiasis que se da a la vera del Nilo y en ningún otro sitio, la podagra en el Ática y el mal de ojos en Acaya. En la primera prueba etiam hace dudar de si se trata de un segundo miembro de la ratio o del inicio de la confirmatio; nonne uides etiam caeli nouitate et aquarum / temptari procul a patria quicumque domoque / adueniunt ideo quia longe discrepitant res ? Pero ideo quia deja bien claro que estamos ante una confirmación que identifica en la diversidad de atmósferas y ambientes la causa de la morbilidad. Habría que traducirlo de forma enfática: «¿no ves que hasta los viajeros enferman... precisamente por cambiar de clima?». La focalización se produce además mediante interrogaciones e interpelaciones al lector (nonne uides...? nam quid...? Quidue...?) Las alusiones a las distintas y distantes partes del cielo así como a las tierras húmedas hacen hincapié en lo que se diferenciaba en la ratio: per caelum ueniunt.../ de terra surgunt, ubi putorem umida nactast. Los cuatro elementos: vientos, cielos, tierra, agua, de los cuatro puntos cardinales (de Gades al Ponto y de Britannia a Egipto), pueden contaminar según dónde a qué personas, animales y partes del cuerpo. Las diferentes regiones, igual que producen diferencias raciales, producen también diferencias en morbilidad: tum color et facies hominum uidentur / largiter et morbi generatim saecla tenere. Ernout \& Robin ad 1106-1109 recogen la opinión del médico Asclepiades (epicúreo contemporánneo de Lucrecio), que sostiene que el envejecimiento prematuro de los etíopes es producido por someter su cuerpo a un exceso de radiación solar mientras que los bretones eran por contra longevo ${ }^{30}$. La elefantiasis de-

${ }^{30}$ AET. 5.30.6, en Diels, D.G. 443, A. 16. 
muestra la etiología ambiental por su peculiaridad de darse exclusivamente al borde del río Nilo: Aegypti peculiare hoc malum (PLIN.Nat.26.2.8); como la podagra se da sólo en el Ática (Plin.Nat.10.100). Se recoge al final de los tres argumentos la conclusión común:

inde aliis alius locus est inimicus

partibus ac membris; uarius concinnat id aër. 6.1096-1097.

\subsubsection{DE MVTATIONE REI}

Comienza aquí la explicación de la corrupción o conmutación que se produce en los distintos medios por los que se transmite la uis morbida, y en los seres vivos por su consumo: la respiración del aire corrompido y la ingestión de alimentos contaminados.
proinde ubi se caelum, quod nobis forte alienum, commouet atque aër inimicus serpere coepit, ut nebula ac nubes paulatim repit et omne qua graditur conturbat et immutare coactat, fit quoque ut, in nostrum cum uenit denique caelum, corrumpat reddatque sui simile atque alienum. haec igitur subito clades noua pestilitasque aut in aquas cadit aut fruges persidit in ipsas aut alios hominum pastus pecudumque cibatus, aut etiam suspensa manet uis aëre in ipso et, cum spirantes mixtas hinc ducimus auras, illa quoque in corpus pariter sorbere necessest. consimili ratione uenit bubus quoque saepe pestilitas et iam pigris balantibus aegror. nec refert utrum nos in loca deueniamus nobis aduersa et caeli mutemus amictum, an caelum nobis ultro natura corumptum deferat aut aliquid quo non consueuimus uti, quod nos aduentu possit temptare recenti.

Los tres primeros versos (1119-1122) y los cinco últimos (1132-1137) mantienen el tópico que en las dos etiologías anteriores había sido comentario: lo alienum, inimicum, clades noua pestilitasque, y su desplazamiento por los cielos y nubes, así como su depósito en las plantas que nos alimentan y la caída en las aguas que bebemos. Igual que la persona que se expone a viajar corre el riesgo de enfermar por extrañar (alienum) el clima y el medio o por contagiarse de enfermedades endémicas del lugar, los aires y nubes que se desplazan transportan también lo extraño que respiramos y consumimos, se dice en 6.1132-1137. La parte central del parágrafo es la que focaliza la corrupción del ambiente y la contaminación de los seres vivos por el consumo: caelum, / corrumpat reddatque sui simile atque alienum (1123-1124); clades noua pestilitasque $/ . .$. in aquas cadit aut fruges persidit (1125-1126); cum spirantes mixtas hinc ducimus auras /.../ consimili ratione uenit bubus quoque saepe / pestilitas et iam pigris balantibus aegror (1129-132). El proceso se puede describir así: 


\section{Corrupción: cielos, aguas, alimentos, aire $\rightarrow$ respiración, ingesta $\rightarrow$ peste}

La carga nociva que se transmite por el medio, una vez respirada o ingerida, infecta a humanos y animales de forma generalizada produciéndose la peste. Hay que observar que aquí la transmisión es a través del aire ${ }^{31}$, las aguas o alimentos contaminados, que no mediante contacto corporal. Contagia, clades, pestilitas parece que se han de considerar como substancias concretas, dados los verbos que les acompañan: in aquas cadit aut fruges persidit, cessabant apisci e in corpus pariter sorbere necessest; esas sustancias, miasmas, son respiradas e ingeridas: aut ubi gustarat, languebat morte propinqua (1218). Más clara será la expresión posterior (6.1235-1236) de contagio entre personas: nullo cessabant tempore apisci / ex aliis alios auidi contagia morbi; Tucídides utilizará la forma verbal $\alpha \nu \alpha \pi \nu \mu \pi \lambda \alpha \mu$ $\mu \varepsilon \nu o r$ : 'llenarse' (Thuc.2.51.4. Para Nutton es dudoso que la explicación de la peste entre los antiguos haya sido mediante inoculación y transmisión de gérmenes. Desde luego, no es lo mismo saber que hay contagio e incluso indicar las vías de su transmisión, que explicar en qué consiste. Pero seguramente el epicureísmo está más cerca que ninguna otra escuela médica antigua de la teoría del contagio de hoy día; sólo que en esta escuela los gérmenes de la enfermedad no son micro-biológicos, sino micro-estructurales.

\subsection{LA PESTE DE ATENAS EN LUCRECIO Y TUCÍDIDES}

Ya hemos dicho que el episodio lucreciano de la Peste no constituye por sí solo un fragmento autónomo y todavía menos que haya que considerarlo por sí solo el epílogo del libro VI, sino que está en función de exornatio de la tesis etiológica anteriormente defendida y desarrollada (6.1090-1137) mediante el procedimiento etiológico que Tucídides le prestó.

Pero resultará todavía más sorprendente que esa misma secuencia sea la que sigue Lucrecio, como veremos, en su descripción de la Peste de Atenas misma ${ }^{32}$. Bailey, a.1., aun reconociendo como etiología el desarrollo previo del origen de la peste en general, no percibe que también para la Peste (1138-fin) se sigue esa misma dispositio: «Having set out his theory of the causes of pestilence in general, Lucretius illustrates it by a magnificent and ghastly description of the famous plague at Athens in 430 B.C., which forms the conclusion of the book and of the whole poem. Lucretius in his description is closely following that of Thucydides' words».

Y de la comparación de ambos textos (el de Lucrecio y el de Tucídides) sobre la Peste de Atenas, hay que inferir la siguiente conclusión: por seguir Lucrecio a Tucídides en su descripción de la Peste de Atenas (salvo algún momento en que la complementa con escritos hipocráticos) y en la misma secuencia etiológica, hay que con-

\footnotetext{
${ }^{31}$ IsID.Nat.39, parafraseando a Lucrecio dice igualmente: aer corruptus.

32 Para Bailey (1947, p.1138), la Peste se divide en tres partes: I: 1137-1229: «The origin and phenomena of the desease»; II: 1230-51: «Its moral effects»; III: 1252-86: «Its aggravation by the influx of the country population».
} 
cluir que el propio Tucídides ha seguido el mismo tipo de texto etiológico en su descripción de la Peste de Atenas, bien sea de forma científica o bien como mera dispositio retórica (Woodman 1988).

El enunciado performativo en primera persona: $\dot{\varepsilon} \gamma \omega \dot{\delta} \delta \dot{\varepsilon}$ oíó $\tau \varepsilon \dot{\varepsilon} \gamma \hat{\gamma} \gamma \nu \varepsilon \tau o \quad \lambda \dot{\varepsilon} \xi \omega .$. $\tau \alpha \hat{v} \tau \alpha \delta \eta \lambda \omega \sigma \omega$, hecho con decisión casi profesional por Tucídides, parece un guiño al lector sobre la autoridad cuasi-médica que posee. Rosalind Thomas (2006, pp.101102). hace ver el énfasis que pone Tucídides al hacer ese enunciado, aun cuando luego cree que: «Thucydides sets aside the pursuit of causes for the plague, yet this is clearly not the case for the rest of the History: no one would deny that he was interested in causation in the rest of the History) ${ }^{33}$.

Pero esa pretendida incongruencia de Tucídides no es tal. Como dice H.F.J. Horstmanshof (1989, p.57):«die Pestbeschreibung... ihre Zielsetzung und ihre Methode mit der Zielsetzung und Methode des ganzen Werkes zusammenfallen». En efecto, en 1.22.24 hablando Tucídides de su quehacer como historiador afirma: «... en cuanto a los acontecimientos que tuvieron lugar en la guerra,... relaté cosas en las que yo mismo estuve presente o sobre las que interrogué a otros con toda la exactitud posible... Me conformaría con que cuantos quieran enterarse de la verdad de lo sucedido y de las cosas que alguna vez vayan a ser iguales o semejantes según la ley de los sucesos humanos, la juzguen útil. Pues es una adquisición para siempre y no una obra de concurso que se destina a un instante». Y en 1.23.4-6 se habla del «porqué de la ruptura, de las causas y divergencias... la causa más verdadera...» de la guerra, que es el objeto de la obra. ${ }^{34}$

Esa coincidencia de los dos momentos de la obra Guerra del Peloponeso hace más verosímil el uso compositivo de la etiología de la Peste por parte de Tucídides y el manejo cuasi-médico con que se desenvuelve el autor. Creemos que Tucídides ha seguido una dispositio propia de una etiología pronóstico ${ }^{35}$, al menos mientras la describe en su aspecto físico o médico (no en las implicaciones sociales que conlleva a partir de 2.53 y sigs.: la anomia, prácticas religiosas, las actitudes existenciales, etc.); es decir, precisamente los rasgos de la descripción en que coinciden los dos autores, Tucídides y Lucrecio, según vamos a ver.

Desde esta coincidencia metodológica de ambos autores en el procedimiento etiológico que siguen, que es propio de Demócrito, de la Medicina empírica y de Epicuro, es desde donde se puede entender por qué Lucrecio adoptó y acopló a sus fines el episodio de la Peste de Tucídides ${ }^{36}$. No puede hacérsele radicar sólo en motivaciones

\footnotetext{
${ }^{33}$ Sigue la opinión de Gomme a.1.: «He therefore contents himself with a description of its symptoms, and of its moral and political effects. This is in apparent contrast with the way in which he deals with the causes of the war, which occupy the greater part of book i».

${ }^{34}$ Rechenauer (1991), plantea la influencia de la Medicina hipocrática sobre Tucídides en este aspecto metódico y constructivo, haciendo ver lo que en el $P B$ hay de «Aitiologie historischer Vorgänge». Es inmensa la bibliografía sobre la «immanente geschichtliche Kausalität» en Tucídides. Cf. Rechenauer (1991, pp. 24-25 y notas).

35 Para ser reconocida en el futuro si se vuelve a dar.

${ }^{36} \mathrm{Si}$ se quiere ver un primer ensayo etiológico en el resumen de la Guerra del Peloponeso de 1.23, pueden

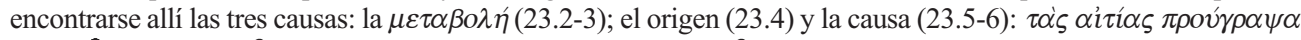

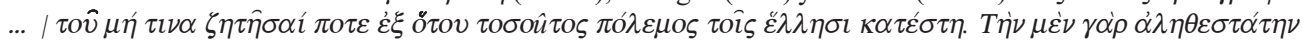
$\pi \rho o ́ \phi \alpha \sigma \imath \nu, \alpha \phi \alpha \nu \varepsilon \sigma \tau \alpha^{\prime} \tau \eta \nu \delta \varepsilon \lambda \sigma^{\prime} \omega \omega$. Cochrane (1965, p.28): «The canons of interpretation employed for the prognosis of the plague seem to us to be the canons employed also in the interpretation of Greek history generally».
} 
literarias (aun cuando tuvieran también su peso): así como la Peste sigue a la euforia del Discurso de Pericles, la Peste sigue al Progreso estudiado en el libro V en Lucrecio (Stoddard 1996, pp.126-127). Sencillamente y mejor, Lucrecio ve la Peste tucidídea totalmente apta desde un punto de vista metodológico y compositivo para confirmar mediante exornatio la etiología precedente sobre el origen de la enfermedad y la peste (6.1090-1137), en que está incrustado el episodio de la Peste (6.1130-fin).

Al mismo tiempo es desde esta coincidencia metodológica desde donde se han de dilucidar las discrepancias que se observen entre los textos de los dos autores: las diferencias filosóficas, de género, de estilo y de función que existan. No basta con conocer las discrepancias que se dan entre las dos versiones de la Peste, la de Tucídides y la de Lucrecio; eso es necesario pero insuficiente si se quiere encontrar el sentido diferente de los dos textos.

\title{
2.2.1. ORIGEN: VNDE ORTVM SIT
}

\begin{abstract}
Haec ratio quondam morborum et mortifer aestus finibus in Cecropis funestos reddidit agros uastanitque uias, exhausit ciuibus urbem. nam penitus ueniens Aegypti finibus ortus, aëra permensus multum camposque natantis, incubuit tandem populo Pandionis omni. 1138-1143 ${ }^{37}$
\end{abstract}

«Esta es la explicación de aquella infección mórbida y el brote potente de muerte...», es a mi juicio la traducción correcta de haec ratio quondam morborum, y remite al v. 6.1090 nunc ratio quae... expediam; esta es la traducción de José Kany-Turpin: «telle est la cause de la peste...». No se ha de entender haec ratio... morborum como «esta forma de pestilencia» (V. Fiol), o «C'est cette forme d'épidémie» (Ernout) o «questa forma di epidemia» (Paratore y Pizzani), o como Bailey (a.l.): «a plague such as this once laid waste... $\rangle^{38}$. Estas traducciones adolecen del mismo defecto: que no han reconocido la función etiológica que desempeña el episodio de la Peste como confirmación (aunque sea exornativa) de la etiología que se propuso en 6.1090: Nunc ratio quae sit morbis aut unde... mortiferam possit cladem... ${ }^{39}$

El hecho histórico de la Peste de Atenas es descrito por Tucídides y es rememorado por Lucrecio; ocurrió desde el verano del año 430 a.C. hasta el verano del 428;

\footnotetext{
${ }^{37}$ El tópico se ha dejado en letra normal sin marcar: morborum et mortifer aestus, funestos reddidit agros. Se ha marcado en negrita lo relativo a la etiología unde ortum sit, que se señala también mediante el marcante temático nam.

${ }^{38} \mathrm{Su}$ interpretación posterior: «such as has been described»-p.1726- me parece mejor.

39 «Esta es la explicación de aquella infección mórbida y el brote potente de muerte que volvió funestos los campos de la tierra de Cécrope, que dejó solitarios sus caminos, que vació de ciudadanos la capital. Viniendo del fondo de Egipto, en donde había nacido, atravesó vastísimos espacios por el aire y las llanuras fluctuantes del mar y se aposentó finalmente en la población de Pandión de forma masiva». Hasta aquí coincide Lucrecio con Tucídides 2.48.1-2, omitiendo aquel las conexiones de la Peste con la narración de la Guerra del Peloponeso; y también parte del recorrido: ¿quizás porque podría indicar una transmisión por la marinería y no por las vías lucrecianas del aire, las nubes, etc.?
} 
se cortó la peste y rebrotó en el invierno del 427/6 una segunda vez hasta el invierno del 426/5; duró por tanto cinco años. Fue una peste muy encarnizada que acabó con un cuarto/un tercio de la población. El contexto en que se introduce es diferente: dentro de la narración de la Guerra del Peloponeso en el caso de Tucídides y de forma argumentativa por Lucrecio.

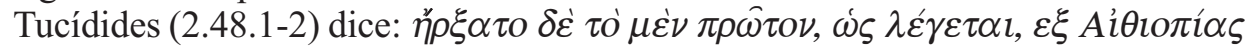

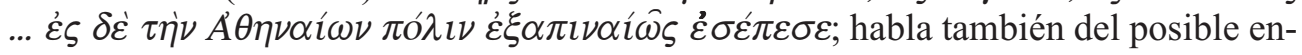
venenamiento de los pozos del Pireo, cosa que omite Lucrecio. ¿Por qué? A este no le importa tanto indagar la etiología de la peste histórica de Atenas, cuanto ofrecer una explicación plausible de la peste en general; y quizás también porque distingue entre envenenamiento y contagio; las sospechas de envenenamiento distraerían del enfoque que el autor le da a la peste como contagio colectivo de unos a otros.

\subsubsection{DE MVTATIONE RERVM $=\mu \varepsilon \tau \alpha \beta O \lambda \eta ́$}

Se acusan ahora las transformaciones y disfunciones fisiológicas y psicológicas que producía la peste mediante la enumeración de los síntomas: los sufrimientos de tipo físico y psíquico de que adolecen los pacientes contaminados hasta llegar a la agonía. Titulamos esta parte como $\mu \varepsilon \tau \alpha \beta o \lambda \eta ́$ o mutatio rerum porque la Medicina hipo-

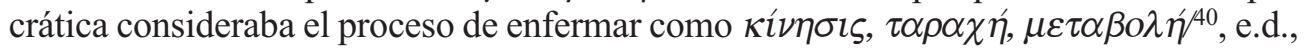
un desorden, un proceso, un estremecimiento y un movimiento errático, una disolución o descomposición de las sustancias de que se componen los cuerpos con la correspondiente disfunción, sufrimiento e incluso muerte ${ }^{41}$.

Lucrecio acusará la influencia de Tucídides, por más que a veces calque escritos hipocráticos. Se inicia su descripción de los síntomas con la frase: inde cateruatim morbo mortique dabantur (1144), que hace de tópico a la descripción de los síntomas progresivos de descomposición de los afectados. Se van recorriendo los distintos miembros del cuerpo siguiendo el eje cabeza-extremidades desde los vv. 6.11441181: cabeza (1145-1146), fauces (1147-1150), pecho y corazón (1151-1167), vísceras (1168-1181). Esa secuencia es canónica en la Medicina hipocrática, pero también es seguida por Tucídides: «La enfermedad recorría todo el cuerpo, de arriba abajo, comenzando primero por asentarse en la cabeza...». Los términos focalizan los síntomas de disfunción de los distintos miembros de forma intensiva mediante la enumeración asindética; el estilo es el de una percursio que describe los síntomas rápida y económicamente. El fragmento describe la mutatio rerum (1119-1137) o $\mu \varepsilon \tau \alpha \beta o \lambda \eta \dot{\eta}$ que se produce en los apestados.

Se describe seguidamente la agonía que sufrían los contaminados en el momento crítico: multaque praeterea mortis tum signa dabantur (6.1182-1196). Para Munro, a.1., el poeta «seems to forget for the time that he is describing the gradual process

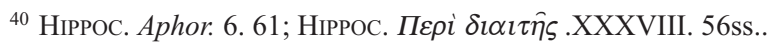

41 Tucídides dice que no había habido antecedentes de tal enfermedad y que las demás quedaron absorbi-

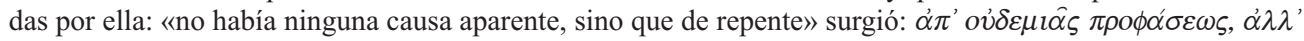

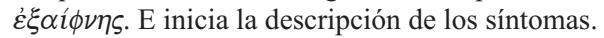


of a disease»; no creo que se dé un salto temático: hasta ahora se describía el proceso en una secuencia anatómica y ahora el proceso es de tipo temporal. La tensión agónica se marca mediante una descripción paratáctica a la carrera. La única marca de unión es un -que enclítico que une con el párrafo anterior y otra partícula de unión: item que hace como de respiro para otra sarta de miembros paratácticos sin partícula que une los distintos miembros. Es un fragmento muy expresivo; nuestro autor lo ha escrito con la libertad que le daba el no tener que seguir al pie de la letra a Tucídides, ya que se da una aemulatio más que una imitatio. La fuente en este caso son los escritos hipocráticos. Praenot. Coac. 93. Prognostikon 8; 5.123; 6.124; 4.123; $2.145 \& 114 \& 118$.

Seguidamente (6.1197-1207): octauoque fere candenti lumine solis /.../... tamen in neruos huic morbus et artus ibat / et in partis genitalis corporis ipsas, se describe la recaída de aquellos que se salvaban de la crisis. Se retoma el texto de Tucídides (2.49.6), al que se sigue no al pie de la letra y ni tan siquiera oración por oración.

Finalmente Lucrecio (6.1208-1214): et graviter partim metuentes limina leti, describe la reacción del instinto de supervivencia, el 'agarrarse a la vida' ante el vértigo que produce el precipicio de la muerte («el susto de verse al borde de la muerte», V. Fiol) a costa o a pesar de las graves mutilaciones y pérdidas de miembros y psicológicas que sufrían: neque se possent cognoscere ut ipsi. Lucrecio dramatiza la descripción seca de Tucídides: pérdida de los ojos y amnesia.

\subsubsection{QVAE CAVSA ID EFFECERIT $=\alpha i \tau \imath i \alpha$. VIS MORBIDA $=\delta v ́ v \alpha \mu \iota \varsigma$}

En este momento se pasa de los síntomas y trastornos a la caracterización de la peste en lo que tiene de específico, lo que la convierte en peste: su capacidad

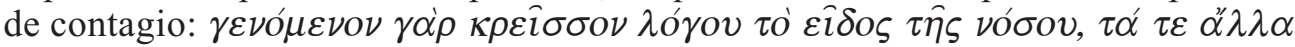

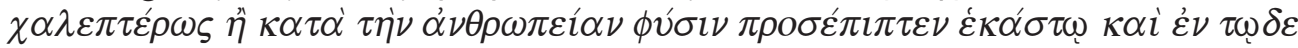

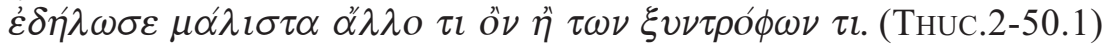

La función de esta última parte es enfatizar la capacidad morbosa de los semina rerum, esa causa dinámica, ese brote enérgico capaz de producir semejante infección

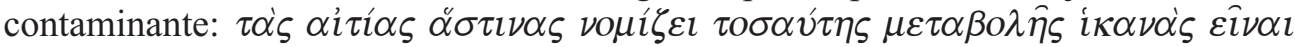

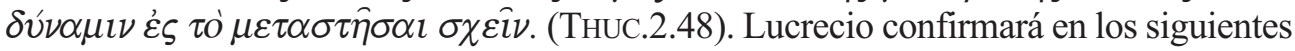
párrafos la causa expresada en 6.1093-1096: ... multarum semina rerum /... quae sint morbo mortique necessest / multa uolare...

En la Medicina hipocrática y en Tucídides (y por tanto en Lucrecio) se busca un 'porqué' explicativo, un tipo de causa dinámica diferente de la causa eficiente de Aristóteles. Vegetti (1999) señala que Aristóteles en su definición de los distintos tipos de causalidad en Physica II y Metaphysica V no acaba de comprender la Antiqua Medicina hipocrática ${ }^{42}$. La $\alpha i \tau i ́ \alpha$ o causa tucidídeo-lucreciana está llena de $\delta v v \alpha \mu \iota \varsigma^{43}$, de uis morbida que se trasfiere a los apestados. Esas partículas van propagando la

\footnotetext{
42 Sobre la causa también en SEXT.EMP. $M$. IX y $P$. III cap. 2-4.

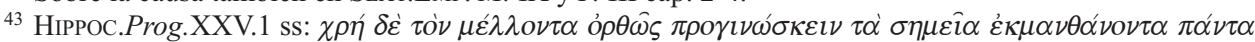

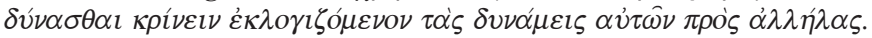


muerte por su volatilidad, por respirarlas e ingerirlas: cum spirantes mixtas hinc ducimus auras, / illa quoque in corpus pariter sorbere necessest (1129-1130).

Esa uis morbida es tan grande que produce incluso el contagio de los animales: multaque humi cum inhumata iacerent corpora supra /.../ extorquebat enim uitam uis

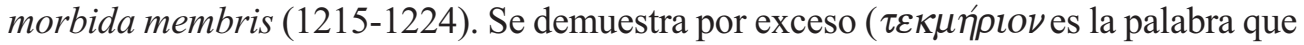
usa Tucídides (2-50.2) y también: $\kappa \alpha i \dot{\varepsilon}^{\varepsilon} \nu \tau \omega \delta \varepsilon \varepsilon \dot{\varepsilon} \delta \dot{\eta} \lambda \omega \sigma \varepsilon \mu \alpha \alpha^{\prime} \lambda \sigma \tau \alpha$ [2.50.1]) lo contagiosa que era la peste, cuando incluso los animales carroñeros no se atrevían ni a respirar el aire contaminado, menos aún a probar la carne de los cadáveres; no salían de sus guaridas: «demostró que era algo bien distinto de las afecciones corrientes el que las aves carroñeras y animales que se alimentan de cadáveres no se acercaban». El perro fiel era el único en morir, aullando lastimeramente por las calles.

Tucídides insiste en la extrañeza $(\alpha \dot{\tau} \tau \pi \dot{\alpha} \alpha)(2.51 .1)$ de algunos síntomas y en el

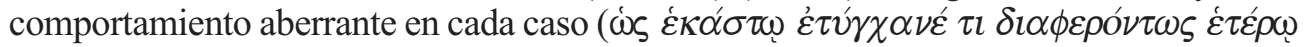

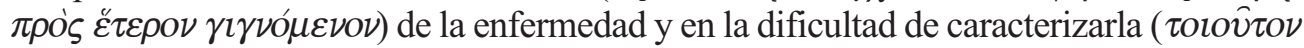

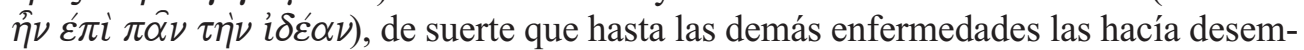
bocar en ella. Lucrecio lo sigue en ello. No había además remedios contra el contagio: nec ratio remedii communis certa dabatur, 1226-122944. No se conocía la causa concreta de tanto contagio ni el correspondiente antídoto.

No hubo ni hay hoy un diagnóstico cierto sobre las causas de la peste histórica de Atenas. Si fue la viruela la causa, como sostienen R. Kobert (1899, pp.240-246) y B. Von Hagen (1938, pp.120-127), o si fue el sarampión, como sostuvo Shrewsbury (1950, pp.1-25). Si fue tifus exantemático, R. Crawford (1914, pp.23-29); si peste bubónica o gripe pandémica, como sostienen A.D. Langmuir, D. Worthen y J. Salomon et alii (1985, pp.1037-1050); o fiebre tifoidea, escarlatina, fiebres de Malta o brucelosis, leptospirosis icterohemorrágica, tularemia; fiebre de Evola, etc. O sencillamente envenenamiento, como también se sostiene. Y por lo tanto tampoco había un remedio o contraveneno específico para contrarrestar la causa que lo producía.

De la causa por tanto no llegamos a saber más que la causa filosófica: los semina con uis morbida, pero no qué semina en concreto eran los que lo producían. No hace Lucrecio un diagnóstico sobre la causa concreta de la Peste de Atenas: nec ratio remedii communis certa dabatur (1226). Su objetivo no es médico sino filosófico: hacer ver cómo se produce el contagio masivo e intenso de la peste en general. La Retórica antigua distinguía dos clases de etiología, la quaestio $=$ thesis, y la causa $=$ hypothesis . Lo que diferencia a una thesis o quaestio de una hypothesis o causa es su mayor grado de generalización, lo que la convierte en filosófica; aun cuando Cicerón (Top. 82) haga de la investigación de la causa el método común a la filosofía, a las ciencias y a la práctica forense. El episodio lucreciano de la Peste trata de confirmar la etiología de tipo thesis (LuCR.6.1093-1096). Por su parte, la etiología de la Peste en Tucídides es de tipo pronóstico ${ }^{45}$; él pretende tan sólo caracterizarla, identificar el síndrome (no dar la causa concreta), para que se la reconozca, si se da en el futuro. Una cosa es ca-

\footnotetext{
${ }^{44}$ El v. 1225: incomitata rapi certabant funera uasta puede muy bien trasladarse a 1237.

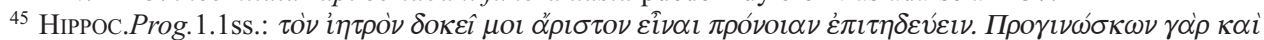

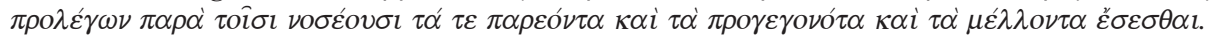


racterizar o describir el tipo de peste y otro identificar la causa concreta; la Retórica clásica distinguía, como se sabe, entre el status quaestionis quid sit y el an sit.

En el fragmento siguiente: Illud in his rebus miserandum magnopere unum / aerumnabile... /.../ funera respectans animam amittebat ibidem (LUCR.6.1230-36, $245)^{46}$, se habla de un aspecto psico-físico, la desesperación de los afectados, que constituía un factor de muerte añadido. Puede parecer exagerado que la desesperación produzca la muerte; pero también Tucídides (2.51.4) mantiene que la $\alpha \theta v \mu i ́ \alpha$ privaba de la capacidad para resistir a la peste ( $\kappa \alpha i \tau o ̀ \nu \pi \lambda \varepsilon \hat{\imath} \sigma \tau o \nu \phi \theta o ́ \rho o \nu \tau o \hat{\tau} \tau o$ $\varepsilon \mathcal{\varepsilon} \varepsilon \pi o i \varepsilon \imath$ ). Es como un círculo vicioso: la reacción ante una muerte cierta, considerada como una condena a muerte, era de desesperación y la desesperación llevaba a la muerte: deficiens animo maesto cum corde iacebat / funera respectans animam amittebat ibidem $^{47}$.

La fuerza mórbida se transmitía de unas personas a otras de forma devastadora:

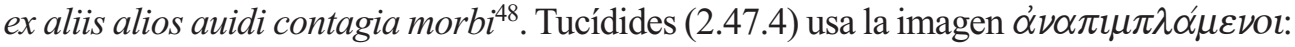
«llenándose...cuando entraban en contacto». Se señala uno de los factores de contagio más importantes, la atención a los parientes: muchos desasistían a sus parientes por miedo al contagio y otros dentro de su impotencia se esforzaban por cumplir con el obsequio de los funerales (6.1237-1246): idque uel in primis cumulabat funere fu$n u s . .$. Habría que ver la referencia de id-que: id es anafórico y remite a los tres últimos versos que preceden: quippe etenim nullo cessabant tempore apisci / ex aliis alios auidi contagia morbi, / lanigeras tam quam pecudes et bucera saecla (6.1235-1236,1245) pero también es catafórico, ya que apunta a nam que introduce la razón enfatizada: «y eso sobre todo ocurría porque...»nam qui cumque suos fugitabant uisere ad aegros /.../ qui fuerant autem praesto, contagibus ibant /.../ optimus hoc leti genus ergo quisque subibat, 1138-1246. Lucrecio sigue a Tucídides hasta el momento (51.6) en que habla de los que sobrevivían y la esperanza de inmortalidad que abrigaban. No tiene que extrañar que la anécdota le pareciera al epicúreo inadecuada o que sencillamente la rechazara; en efecto, Holladay y Poole (1982, pp.235ss.) afirman que Tucídides demuestra tener conocimientos más avanzados que la Medicina de su época al reconocer esta «specific acquired immunity». Se suele señalar desde Munro una laguna entre el verso 1246 y el siguiente, laguna que aprovechó Bockemüller para trasladar los versos 1246-1251 al final del libro.

La llegada a Atenas de los campesinos (que venían ya afectados desde sus aldeas) y su hacinamiento en pleno verano es otro factor que agrava la Peste e incrementa el número de apestados: Praeterea iam pastor et armentarius omnis /.../ulceribus taetris prope iam sordeque sepulta. (6.1252-1271) El fragmento describe las calles llenas de moribundos y cadáveres.

Sigue después el párrafo dedicado a los ritos funerarios (6.1272-1286), que considero continuación del anterior, en el que se describe a los moribundos tirados por las calles y que ahora se alojan o sus cadáveres van a parar a los templos: omnia denique

\footnotetext{
${ }^{46}$ El v. 1245 se ha localizado tras 1236 porque es una frase que en Tucídides sigue a este enunciado.

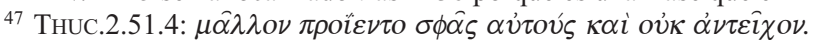

${ }^{48}$ Contagia morbi aparece sustantivado; sería lo equivalente a semina.
} 
sancta deum delubra replerat /.../ rixantes, potius quam corpora desererentur (6.12721286). La partícula enumerativa denique indicaría algo así como 'para acabar'; lo cual denota que estamos ante el final de una sarta de párrafos (nos encontraríamos en el final total) o al menos al final del último párrafo, el que ha enfatizado el hacinamiento de la población (lo que indicaría la continuidad del mismo tema).

Casi todos los editores han subrayado, en cambio, como denominador común del fragmento la frase nec iam religio diuom nec numina magni / pendebantur enim: praesens dolor exsuperabat (6.1276-1277), como si de lo que tratara fuera del menosprecio de la religión, y no simplemente de la mortandad que producía la peste, que igual que llenaba la calle de cadáveres, llenaba también los templos. Se debe observar que los que toman en el De rerum natura la iniciativa de alojar a los apestados y pordioseros e incluso utilizar los templos como depósitos de cadáveres, no son las gentes movidas por un supuesto desprecio a los lugares sagrados (quien sí lo dice es Tucídides

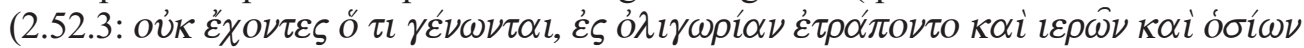

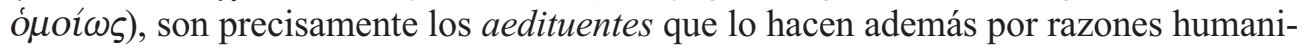
tarias: «el dolor apremiaba por encima de cualquier consideración». Los enterramientos constituían un aspecto importante del culto que se vio depreciado por el estado de necesidad; creo que habría que traducir con énfasis nec mos ille sepulturae por: «ni tan siquiera el rito fúnebre de la inhumación se observaba, rito con el que había acostumbrado aquel pueblo a enterrar a sus muertos»; no se podían seguir haciendo los enterramientos con la ceremonia y dispendio acostumbrados por falta de medios. La incineración, que sustituye al enterramiento, se hace para abreviar el funeral y ahorrar medios, hasta el punto de tener que robar los parientes las piras de otros.

Es necesario añadir a los últimos versos del De rerum natura, para completar este último aspecto de la falta de recursos para los sepelios y también para redondear el final del libro y de la obra (de lo contrario el final sería demasiado abrupto) los vv. 6.1237-1251 que desde Bockemüller se suelen trasladar aquí; además puede hacérseles preceder del v. 1225 del mismo tema (con Stoddard a.1.):

incomitata rapi certabant funera uasta

inque aliis alium populum sepelire suorum

certantes, lacrimis lassi luctuque redibant;

inde bonam partem in lectum maerore dabantur.

Nec poterat quisquam reperiri, quem neque morbus

nec mors nec luctus temptaret tempore tali.
1225

$6.1247-1251$

Lucrecio no continúa hablando como hará Tucídides (2.53.1) de la anomia que se produjo en Atenas. La razón, pienso, es que el episodio de la Peste cumple estrictamente la función de exornatio de la etiología física sobre el origen de la enfermedad y la peste que Lucrecio se había propuesto.

En conclusión, en los vv. 6.1090-1251 del De rerum natura de Lucrecio y desde 2.48.1 hasta 2.52.4 de la Guerra del Peloponeso de Tucídides, ambos autores desarrollan el episodio de la Peste de Atenas siguiendo de forma coincidente el modus tractandi de una etiología triple: $\alpha \phi^{\prime}$ ó $\tau o v=$ unde ortum sit; $\mu \varepsilon \tau \alpha \beta \delta \lambda \eta \dot{\eta}=$ de mutatione rei; $\tau \alpha \alpha_{\varsigma} \alpha i \tau i \alpha \varsigma=$ quae causae id effecerint. La Peste de Atenas en Lucrecio 
(6.1138-1286) no es un fragmento autónomo sino una exornatio del argumento etiológico que la precede (6.1090-1137); pero al ser una confirmación del argumento y al seguir el guión de Tucídides, reitera la estructura de esa triple etiología.

\section{REFERENCIAS BIBLIOGRÁFÍCAS}

\subsection{TUCÍDIDES}

Ediciones, comentarios y traducciones:

Romilly, J. de - L. Bodin - R. WeIL (1953-1972), Thucydide, París, Les Belles Lettres, 5 vol. HiPPOCRATICUM CORPus (1973), La collection hippocratique, Collection de Strasbourg, Leiden. Gomme (1982), A historical Commentary of Thucydides, Oxford, Clarendon Press.

Hornbower, S. (1991), Commentary on Thucydides, Oxford, Clarendon Press.

Betant, E.A. (1969), Lexikon Thucydideum, Hildesheim, Olms.

CAlonge, J. (1990-91), La Guerra del Peloponeso. 3 vols. Madrid, Gredos.

Guzmán Guerra, A. (1989), Tucídides: Historia de la Guerra del Peloponeso, Madrid, Alianza Editorial.

\section{Crítica:}

Cochrane, CH.N. (1965), Thucydides and the Science of History, Nueva York: Russell\&Russell. Demont, P. (1983), «Notes sur le récit de la pestilence athénienne chez Thucydide et sur ses rapports avec la médicine grecque de l'époque classique», en LASSERRE, F. - MUDRY, PH. (eds.), Formes de pensée dans la collection hippocratique, Ginebra, Libraire Droz S.A., pp. 341-347.

EIJK, PH.J. van DER (1997), «Towards a Rhetoric of Ancient Scientific Discourse. Some Formal Characteristics of Greek Medical and Philosophical Texts», en BAKKER, E.J. (ed.), Grammar as Interpretation. Leiden, Brill, pp.77-129.

EIJK, Ph. J. vAN DER (2005), «Hippocrates in Context», en XIth International Hippocratic Colloquium, University of Newcastle upon Tyne 2002, Leiden, Brill, pp.287-294.

Finley, J.H. (1948), Thucydides, Oxford, Oxford University Press.

Greenwood, M. (1921), «Galen as an epidemiologist», Proc. Roy. Soc. Med., Sect. Hist. of Med. 14.3-16.

Grimm, J. (1965), Die literarische Darstellung der Pest in der Antike und in der Romania, München, Fink.

GrMeK, M.D. (1984), «Les vicissitudes des notions d'infection, de contagion et de germe dans la médecine antique», en Textes Médicaux Latins Antiques, Mémoires du Centre J. Palerne, Saint-Étienne, pp.53-70.

Holladay, A.J. - Poole, J.C.F., (1982), «Thucydides and the Plague of Athens», CQ 32.282300.

Hope, V.M. - Marshall, E. (2000), Death and Disease in the Acient City, Londres, Routledge. Horstmanshoff, H.F.J. (1989), «Epidemie und Anomie», en KüMmel, W.F., Alte Medizin, Stuttgart, pp.43-66. 
Langmuir, A.D. - Worthen, D. - Salomon, J. et alii (1985), «The Thukydides Syndrome», New English Journal of Medicine 313, pp.1037-1050;

LEVEN, K.H. (1997), Die Geschichte der Infektionskrankheiten : von der Antike bis ins 20. Jahrhundert. Landesberg/Lech, Ecomed.

Lichtenthaeler, Ch. (1965), Thucydide et Hippocrate vus par un historien-médecin, Genève: Droz.

Longrigg, J. (2000), «Death and Epidemic Disease in Classical Athens», en Hope, V.M. Marshall, E., Death and Disease in the Ancient City, Londres, Routledge, pp.55-64

NutTon, V. (1983), «The seeds of desease: an explanation of contagion and infection from the Greeks to the Renaissance», Medical History.27.1-34.

Page, D.L. (1953), «Thucydides' Description of the Great Plague at Athens», CQ 3.97-119. PARry, A. (1969), «The language of Thucydides' Description of the Plague», BICS 16.106 y sigs. Perez Zaragorin (2005), Thucydides, Princeton Univ. Press.

Proctor, D. (1980), The experience of Thucydides, Warminster, Aris\&Philips.

Rechenauer, G. (1991), Thukydides und die hippokratische Medizin, Hildesheim, Olms.

Rodríguez Alfageme, M.I. (1981), La medicina en la comedia Ática, Madrid.

Romilly, J. DE. (1956), Histoire et raison chez Thucydide, París, Les Belles Lettres.

Shanske, D. (2007), Thucydides and the Philosophical Origins of History, Cambridge U.P. Shrewsbury (1950), «The Plague of Athens», Buletin of the History of the Medicine 24.1-25. SteEl, D. (1981), «Plague Writing. From Boccaccio to Camus», Journal of European Studies 11.88-110.

Sudhoff, K. (1915), «Vom 'Pestsamen' des Galenos», Mitteilungen zur Geschichte der Medizin und der Naturwissenschaften 14.227-229.

Thomas, R. (2006), «Thucydides' intellectural milieu and the Plague», en Rengakos, A. Tsakmakis, A., Brill's Companion to Thucydides, Leiden-Boston, Brill.

Vegetti, M. (1999), «Culpability, Responsability, Cause: Philosophy, Historiographie and Medicine in the Fifth Century», en LONG (ed.), Cambridge Companion to Early Greek Philosophy, Cambridge University Press, pp.271-289.

VINTRÒ, E., (1968), «Tucídides y Sófocles ante la peste», BIEH II/2.57-64.

WeIDAuer, M. (1954), Thukydides und die hippokratischen Schriften, Heidelberg, C. Winter. Woodman, A.J. (1988), Rhetoric in Classical Historiography, Portland, Areopagitica Press.

\subsection{LUCRECIO Y EPICÚREOS}

Ediciones, traducciones

Munro, H.A.J. (1864), T. Lucreti C. libri sex., 2 vols., Cambridge.

BAILEY, C. (1947), T. Lucreti C. De rerum natura, Oxford, Oxford University Press.

ERnout, A. (1964), Lucrèce : De la Nature, París, Les Belles Lettres.

Fiol, V. (1961), Lucrecio. Sobre la Naturaleza, Madrid, Alma Mater.

KanY-Turpin, J. (1998), Lucrèce. De la nature, París, Flammarion.

Roca MeliÁ, I. (1989), Lucrecio Caro. La naturaleza, Madrid, Akal.

Usener, H. (1963), Epicurea, Roma, L'Erma di Bretschneider. 
Diels, H. (1879), Doxographici graeci, Berlin, Weidmann, reed. Walter de Gruyter, 1965.

Drabkin, I.E., Caelius Aurelianus. On Chronic Diseases, Chicago, Chicago University Press. Martin Garcia, F. (1987), Plutarco. Charlas de sobremesa, Madrid, Gredos.

\section{Crítica:}

AdAM, J.M. (1997), Les Textes: types et protypes, París, Nathan.

Algra, K. (ed.) (1997), Lucretius and his intellectual Background, Amsterdam, Royal Netherlands Academy of Arts and Science.

André, J.-M. (1980), «La notion de Pestilentia à Rome: du tabou religieux à l'interprétation préscientifique», Latomus 39.3-16.

Asmis, E. (1984), Epicurus' Scientific Method, Ithaca and London, Cornell University Press.

BAyet, J. (1948), «Études lucrétiennes», en Cahiers du Collège philosophique, París.

Bignone, E. (1945), Storia della Letteratura Latina, Florencia, G.C. Santoni.

Bodson, L. (1991), «Le vocabulaire latin des maladies pestilentielles et épizootiques», En SABBAH, J. (ed.), Le latin médical, Saint-Étienne, pp. 215-241.

Bollack, M. (1978), La raison de Lucrèce, París, Éditions de Minuit.

BRIGHT, D.F. (1971), «The Plague and the Structure of De rerum natura», Latomus 30.607-632.

BÜCHNER, K. (1977), Humanitas Romana, Heidelberg, Winter.

Clay, D. (2001), Paradosis and survival: three chapters in the history of Epicurean philosophy, Michigan University Press.

Commager, H.S. Jr. (1957), «Lucretius' Interpretartion of the Plague», Harvard Studies in Classical Philology, 62.105-118.

Commager, H.S. - Bright - Godwin (eds.). (1991), Lucretius De rerum natura VI, Warminster, Aris and Phillips.

Duhot, J.J. (1989), La conception stoïcienne de la causalité, París, J. Vrin.

FARrell, J. (2007), «Lucretian Architecture: The Structure and Argument of the De Rerum Natura», en Gillespie, S. - Hardie, Ph. (eds.), The Cambridge companion to Lucretius, Cambridge, UK, Cambridge University Press.

FilipetTi, A. (2007), «Ippocrate e Lucrezio», AION (filol.) 29.127-134.

Foster, E. (2009), «The Rhetoric of Materials: Thucydides and Lucretius», American Journal of Philology 130.3.367-397.

Gale, M. (2007), Litterary Criticism, Oxford, Readings in Classical Studies.

Giancotti, F. (1980), L'ottimismo relativo nel 'de rerum natura' di Lucrezio, Turin, Loescher. Hugo, Victor (1986), Les Contemplations, XXX, Magnitudo parvi, París.

Kenney, E.J. (1977), Lucretius, Greece and Rome New Surveys in the Classics 11, Oxford, Oxford University Press.

Kroll, W. (1936), Das Epicheirema, Viena, Sitzungsberichte der Akademie der Wissenschaften in Wien, Philos. Hist. K1., 216, 2.

LogRé, B. J. (1946), L'anxieté de Lucrèce, París, J.B. Janin.

Longacre, R.E. (1979), «The Paragraph as a Grammatical Unit», en T. Givón (ed.), Syntax and Semantics, vol. 12: Discourse and Syntax, New York Academic Press, pp.115134.

Luck, W. (1932), Die Quellenfrage im 5. u. 6. Buch des Lukrez, Dissertation, Breslau. 
Milanese, G. (1987), «Osservazioni sulla tecnica argomentativa di Lucrezio», en Montero, T. (ed.), Analysis I. Didascalia, Génova, pp.43-92.

Minadeo (1965), «The formal design of De rerum natura », Arion 4.444-461

PARAtore, E. (1979), Storia della Letteratura Latina, Florencia, Sansoni.

PARAtore, E., Pizzani, U. (1960), Lucreti De rerum natura : logos praecipue notabiles collegit et ill. Hector Paratore. comm. instruxit H. Pizzani, Roma.

Perelli, L. (1968): «Dottrina epicurea e poesia nel De rerum natura di Lucrezio», Atti Acad. Scienze Torino, pp.203ss.

Perelli, L. (1947), «Il piano originario del poema lucreziano alla luce del suo svolgimento ideale», Riv. Filo. Clas., 25.18-43.

PhiLlips, J.H. (1982), «Lucretius on the inefficacy of the medical art», Classical Philology, 77.133-135.

PhilliPs , J.H. (1981), «The etiology of disease: a late Republican view», Proc. 27 Int. Congr. Hist. Med. I, Barcelona, pp.327-330.

Phillips , J. H. (1982), «On Varro's animalia quaedam minuta and etiology of disease», Trans. Stud. Coll. Physns Philadelphia, ser. V. 4, pp.12-25.

Pigeaud, J. (1980), «La physiologie de Lucrece», Rev. Ét. Latines, 58.176-200

Regenbogen, O. (1961), Kleine Schriften, München, Beck.

REIZENSTEIN, Gnomon 9, 1933.542-549

Roca Meliá, I. (1978), «Términos lucrecianos para los conceptos de átomo y de los cuatro elementos», Millars 5.31-48).

Rosa, F. (2007), «Lucrezio e il senso della malattia nel De rerum natura», MedSec, 19(3).763781.

Ruiz Castellanos, A. (1992), La argumentación lógico-retórica del 'De rerum natura'de Lucrecio, Sevilla, Servicio de Publicaciones de la Universidad de Sevilla.

Ruiz Castellanos, A. (1991), «Metaenunciados en el De rerum natura de Lucrecio», Excerpta philologica, pp.767-777

Ruiz Castellanos, A. (1993), «La didáctica latina párrafo a párrafo», en Ruiz CAstellanos, A., Retórica, Texto y Comunicación, Cádiz, Servicio de Publicaciones de la Universidad de Cádiz, pp.172-185.

Runia, D.T. (1997), «Lucretius and Doxography», en Schrijvers - Koenen - Algra (eds.). Lucretius and his Intelectual Background, Amsterdam.

Salemne, S. (1980), Strutture semiologiche nel De rerum natura di Lucrezio, Nápoles, Società Editrice Napoletana.

Segal, Ch. (1990), Lucretius on Death and Anxiety, Princeton Univ. Press.

Schrijvers, P. (1970), Horror ac diuina uoluptas. Études sur la poétique et la poésie de Lucréce, Ámsterdam, Hakkert.

SEDlEY, D. (1998), Lucretius and the Transformation of Greek Wisdom, Cambridge, CUP, reed. 2003.

SIKES, E.E. (1936), Lucretius, poet and philosopher, Cambridge, Cambridge University Press.

StOdDARD, K. (1996), «Thucydides, Lucretius, and the end of the De rerum natura», Maia 48.107-128.

Stok, F. (2000), «Il lessico del contagio», en Radici Colace, P. - Zumbo, A., Atti del Seminario internazionale di studi sulla letteratura scientifica e tecnica greca e latina, Messina 2000, pp.55-89. 
Thivel, A. (1991), «La dénomination des causes des maladies chez Lucrèce», en SABBAH, J. (ed.), Le latin médical. La constitution d'un langage scientifique, Saint-Étienne, pp.243256.

Traglia, A. (1948), Sulla formazione spirituale di Lucrezio, Roma.

WeSt, (1979), «Two Plagues. Virgil, Georgics 3.478-566 and Lucretius, 6.1090-1286», en WeST, D. - Woodman T. , Creative imitation and Latin literature, Cambridge, Cambridge University Press, pp.71-88. 